\title{
Measurement of efficiency of agricultural input and output in Guizhou by data envelopment analysis (DEA) method
}

\author{
ZHANG Fengtai ${ }^{1,2, a}$ \\ ${ }^{1}$ Institute of Environment, Resources and Disaster, Guizhou Normal College, Guiyang 550018 \\ ${ }^{2}$ School of Geographic and Oceanographic Sciences, Nanjing University, Nanjing 210093 \\ azhfthero@126.com
}

Key words: Agriculture; Input and output. Efficiency; Guizhou

Abstract: Using data envelopment analysis (DEA) method, Selecting effective irrigation area, crop planting area, fertilizer inputs, pesticides, rural employed population as input indexes, agricultural output, food production as output indexes, taking Guizhou province as the research object, to measure and analyze the input-output efficiency of agriculture in 2003-2012. The results showed that:(1) The volatility change of comprehensive efficiency of agricultural input and output was smaller nearly 17 years in Guizhou province, generally in a nearly optimal state. Scale efficiency was the main factors influencing the overall efficiency of agricultural input and output in Guizhou. (2) In the case of Variable Return Scale, invalid year of efficiency appeared input redundancy, In the redundant indicators, crop planting area, fertilizer input and pesticide use were bigger; There were excessive reclamation, excessive use of fertilizers and pesticides, by cutting the input redundancy can make agricultural production efficiency to achieve the optimal state. The results of the analysis can provide some useful reference for $t$ ecological environment construction and the sustainable development of ecological agriculture in Guizhou province.

\section{Introduction}

China faced with less stock of agricultural resources, low level of per capita, build a resource-conserving and environmentally friendly agriculture(RCEFA) is especially important and more urgent [1]. Core of RCEFA is to use the advanced irrigation management system and technology, scientific fertilization system, reducing the use of pesticides, fertilizers and plastic time, land, water and energy saving, high efficiency, low energy and intensive circulation system of agricultural production, realizing the sustainable development of agriculture. Over the years, however, with the mass and excessive application of fertilizers, pesticides, the excessive reclamation of land, soil pollution, land degradation, water pollution, soil erosion and other rural environmental problems appeared gradually, as a result, quantitative evaluation of relationship between input and output of the current agriculture, has important practical significance to reduce the excessive investment, intensive production, achieve RCEFA standard and realize the sustainable development of agriculture.

Through analyzing the existing research literature in china, the research on efficiency evaluation mainly focus on total or a single element (water resources, land resources, chemical fertilizer, etc.) of agricultural input and output in the national, provincial scale. Such as Wang bing to measure the efficiency of agriculture and agricultural total factor productivity of China's 31 provinces, and analyze the effect factors of agricultural efficiency and total factor productivity [2]. Wang Xue- 
yuan etc. using the provincial panel data, using the stochastic frontier production function method had estimated the technical efficiency of China's agricultural production and irrigation water use [3]. Liu $\mathrm{Yu}$ etc. had evaluated water resource utilization efficiency of 17 city in $\mathrm{Hu}$ bei province, selection economic and ecological benefit indicators of agricultural water resources, using data envelopment analysis (DEA) [4].Li jing etc. to measure fertilizer use efficiency in major grain producing areas in China, such as, and analyzes the determinants of fertilizer use efficiency [5]. These studies focused on agricultural total factors, single factor productivity, and the study area are mostly in the eastern higher level agricultural development area. Karst widely distributed in Guizhou area, fragile ecological environment, very outstanding contradiction between human and land, the development of RCEFA is a necessary choice, in conformity with current construction of ecological civilization in Guizhou province. But research on agricultural input and output efficiency is relatively little in Guizhou. Therefore, agricultural input and output efficiency is measured and analyzed with DEA model in Guizhou, has reference value for the construction and ecological environment, having reference value for the next development of RCEFA and the ecological environment construction.

\section{Data Envelopment Analysis (DEA)}

DEA is put forward by the United States Charnes, Coopor and Rhodes in 1978, it is a quantitative analysis method of Relative effectiveness evaluation of the same type units based on multiple input index and output index. The comprehensive efficiency can be divided into product of pure technical efficiency and scale efficiency, the comprehensive efficiency can be divided into pure technical efficiency and scale efficiency product by DEA model, DEA model,8,9 [5] as follows:

$$
\left\{\begin{array}{c}
\min \left[\theta-\varepsilon\left(\hat{e}^{T} S^{-}+e^{T} S^{+}\right)\right] \\
\text {s.t } \sum_{j=1}^{n} X_{i} \lambda_{i}+S^{-}=\theta X_{0} \\
\sum_{j=1}^{n} Y_{j} \lambda_{j}-S^{+}=Y_{0} \\
\lambda_{j} \geq 0, j=1, \cdots, n \\
S^{-} \geq 0, S^{+} \geq 0
\end{array}\right.
$$

In the formula, $\lambda_{j}$ as weight variables $; S^{-}$as slack variable; $S^{+}$remaining variables

; $\varepsilon$ as the Archimedes dimensionless; $\theta(0<\theta \leqslant 1)$ as the comprehensive efficiency index

, $\theta$ larger value, the higher the overall efficiency,

, When $\theta=1$, called DEA effective decision making units, indicates that the comprehensive efficiency of agricultural input and output to achieve the optimal; When $\theta<1$, called decision making units DEA is invalid, can by projection on the surface of the decision-making unit in a relatively effective to improve the ineffective decision making units, make, $x_{0=}^{*} \theta x_{0-} s_{i}^{-}$, 
$y_{0=}^{*} \theta y_{0+} s_{j}^{+}, x_{0}^{*}, y_{0}^{*}$ to $x_{0}, y_{0}$ in the production of projection on the surface of the efficient frontier, the effective decision units after the adjusting and optimizing [4,5].

\section{the study area}

Guizhou province is located in the eastern Yunnan-Guizhou plateau, a humid subtropical monsoon climate, four seasons, plenty rainfall, rain heat over the same period, $92.5 \%$ of the area is mountain and hills, Karst landforms are very typical and $109084 \mathrm{~km} 2$, accounting for $61.9 \%$ of the province's land area, therefore, the ecological environment is fragile. Guizhou is a traditional agricultural province, agricultural population and agriculture industry is greater.

\section{Establishment of index system}

Select data from 1996 to 2012 in Guizhou as decision unit, according to the decision making units number at least twice as input and output indexes of DEA model and try to avoid the principle of linear correlation between the indicators, combined with the existing research literature data and availability of date, this study constructed with effective irrigation area (thousand hm2), crop planting area (thousand $\mathrm{hm} 2$ ), fertilizer inputs $(\mathrm{t})$, pesticides $(\mathrm{t})$, rural employed population (ten thousand people) as the input indicators, and agricultural output (one hundred million yuan), food production $(\mathrm{t})$ as the output indexes. From economics, capital, labor, land and other production factors to analysis the efficiency of agricultural input and output in Guizhou. Therefore, this article selects the rural population, and crop planting area to respectively represent the labor and land of basic production factors in economics, selecting effective irrigation area, fertilizer inputs, pesticides for agricultural capital investment. As the data acquisition is difficult, with effective irrigation area representing the construction of water conservancy infrastructure and investment.

In this paper, the index data are from 《Guizhou statistics yearbook》 (1997-2013) and 《China rural statistical yearbook $\rangle$, part of the data obtained from trend prediction.

\section{The results and analysis}

The index data to the DEA model, get the overall efficiency, pure technical efficiency and scale efficiency and slack variables of agricultural input and output nearly 17 years from 1996 to 2012 in Guizhou province, are shown in table 1,2. 
Table1. The results of DEA model

\begin{tabular}{|c|c|c|c|}
\hline Decision making units(MDU) & $\begin{array}{l}\text { Overall efficiency } \\
\qquad(\theta)\end{array}$ & Pure technical efficiency $(\sigma)$ & Scale efficiency(s) \\
\hline 1996 & 0.952 & 1.000 & 0.952 \\
\hline 1997 & 0.955 & 0.993 & 0.962 \\
\hline 1998 & 1.000 & 1.000 & 1.000 \\
\hline 1999 & 0.997 & 1.000 & 0.997 \\
\hline 2000 & 1.000 & 1.000 & 1.000 \\
\hline 2001 & 0.975 & 1.000 & 0.975 \\
\hline 2002 & 0.916 & 1.000 & 0.916 \\
\hline 2003 & 0.967 & 1.000 & 0.967 \\
\hline 2004 & 1.000 & 1.000 & 1.000 \\
\hline 2005 & 1.000 & 1.000 & 1.000 \\
\hline 2006 & 0.875 & 0.946 & 0.925 \\
\hline 2007 & 0.919 & 0.945 & 0.973 \\
\hline 2008 & 0.979 & 1.000 & 0.979 \\
\hline 2009 & 0.990 & 1.000 & 0.990 \\
\hline 2010 & 0.975 & 0.978 & 0.998 \\
\hline 2011 & 0.830 & 0.970 & 0.856 \\
\hline 2012 & 1.000 & 1.000 & 1.000 \\
\hline 均值 & 0.961 & 0.990 & 0.970 \\
\hline
\end{tabular}

Table2. The calculation results of BCC model

\begin{tabular}{|c|c|c|c|c|c|c|c|c|}
\hline MDU & $\theta$ & $\begin{array}{l}\text { Effective } \\
\text { irrigated area } \\
\text { (thousand } \\
\mathrm{hm}^{2} \text { ) }\end{array}$ & $\begin{array}{c}\text { Crop } \\
\text { planting } \\
\text { area } \\
\text { (thousand } \\
\mathrm{hm}^{2} \text { ) }\end{array}$ & $\begin{array}{l}\text { Fertilizer } \\
\text { inputs (Ten } \\
\text { thousand t) }\end{array}$ & $\begin{array}{l}\text { amount of } \\
\text { pesticide } \\
(t)\end{array}$ & $\begin{array}{c}\text { Rural } \\
\text { working } \\
\text { population } \\
\text { (Ten } \\
\text { thousand) }\end{array}$ & $\begin{array}{l}\text { Agricultural } \\
\text { output } \\
\text { (Hundred } \\
\text { million Yuan) }\end{array}$ & $\begin{array}{c}\text { Food } \\
\text { production } \\
\text { (Ten thousand } \\
\text { t) }\end{array}$ \\
\hline 1996 & 0.952 & 0.000 & 0.000 & 0.000 & 0.000 & 0.000 & 0.000 & 0.000 \\
\hline 1997 & 0.955 & 10.515 & 0.000 & 2.832 & 0.000 & 0.000 & 0.592 & 0.000 \\
\hline 1998 & 1.000 & 0.000 & 0.000 & 0.000 & 0.000 & 0.000 & 0.000 & 0.000 \\
\hline 1999 & 0.997 & 0.000 & 0.000 & 0.000 & 0.000 & 0.000 & 0.000 & 0.000 \\
\hline 2000 & 1.000 & 0.000 & 0.000 & 0.000 & 0.000 & 0.000 & 0.000 & 0.000 \\
\hline 2001 & 0.975 & 0.000 & 0.000 & 0.000 & 0.000 & 0.000 & 0.000 & 0.000 \\
\hline 2002 & 0.916 & 0.000 & 0.000 & 0.000 & 0.000 & 0.000 & 0.000 & 0.000 \\
\hline 2003 & 0.967 & 0.000 & 0.000 & 0.000 & 0.000 & 0.000 & 0.000 & 0.000 \\
\hline 2004 & 1.000 & 0.000 & 0.000 & 0.000 & 0.000 & 0.000 & 0.000 & 0.000 \\
\hline 2005 & 1.000 & 0.000 & 0.000 & 0.000 & 0.000 & 0.000 & 0.000 & 0.000 \\
\hline 2006 & 0.875 & 0.000 & 727.887 & 1.600 & 919.741 & 0.000 & 0.000 & 104.281 \\
\hline 2007 & 0.919 & 0.000 & 435.616 & 1.578 & 482.016 & 0.000 & 0.000 & 19.718 \\
\hline 2008 & 0.979 & 14.690 & 309.954 & 0.000 & 1545.094 & 29.446 & 0.000 & 0.000 \\
\hline 2009 & 0.990 & 0.000 & 0.000 & 0.000 & 0.000 & 0.000 & 0.000 & 0.000 \\
\hline 2010 & 0.975 & 165.663 & 565.965 & 0.000 & 1082.513 & 11.473 & 0.000 & 0.000 \\
\hline 2011 & 0.830 & 39.404 & 0.000 & 3.328 & 1601.517 & 0.000 & 0.000 & 189.638 \\
\hline 2012 & 1.000 & 0.000 & 0.000 & 0.000 & 0.000 & 0.000 & 0.000 & 0.000 \\
\hline $\begin{array}{l}\text { Mean } \\
\text { value }\end{array}$ & 0.961 & 13.545 & 119.966 & 0.549 & 331.228 & 2.407 & 0.035 & 18.449 \\
\hline
\end{tabular}




\section{Characteristics of agricultural input and output efficiency in Guizhou province}

(1)From the point of comprehensive efficiency, visible in table 1, the mean value of comprehensive efficiency of agricultural input and output in Guizhou was 0.961 , accounted for $96.1 \%$ of the optimal level, showed that higher agricultural input and output efficiency nearly 17 years. 1998,2000, 2004, 2005 and 2012, comprehensive efficiency value was 1, respectively, and slack variable values are 0, DEA effective, suggested that this five years in Guizhou province agricultural inputs and outputs to achieve the best state. The rest of the comprehensive efficiency values less than 1, as an invalid, but invalid year except 2006 and 2011, other years comprehensive efficiency is above 0.9, showed that almost 17 years in Guizhou agricultural input and output in general in a nearly optimal state. (2) From the point of pure technical efficiency, visible in table 1, the mean value of pure technical efficiency of agricultural input and output in Guizhou is 0.990, accounted for $99.0 \%$ of the optimal level, showed that nearly 17 years pure technical efficiency of agricultural input and output was close to the optimal level. only 1997, 2006, 2007, 2010 and 2011 in 17 years, pure technical efficiency less than 1 , pure technical efficiency is invalid, but more than 0.9 , the pure technical efficiency was not the main factor affected input and output efficiency of agriculture 17 years in Guizhou province. (3) From the point of scale efficiency, visible the table 1, the mean value of scale efficiency of the agricultural input and output was 0.970 , accounted for $97.0 \%$ of the optimal level, showed that nearly 17 years in Guizhou province the scale efficiency of agricultural input and output close to the optimal level. In 12 of 17 years, pure scale efficiency value less than 1, invalid pure scale efficiency, to illustrate the agricultural input and output size and configuration not reasonable, continue to expand the scale of production could get the best economies of scale. Scale efficiency was the main factors influencing the overall efficiency of agricultural input and output in Guizhou. This situation in conformity with the current weak agriculture foundation, bits and pieces of arable land, small scale farming industry. The main direction in the future of agriculture in Guizhou should vigorously develop ecological agriculture, promote the land circulation, increase agricultural industrialization scale.

\section{Optimization analysis}

From table 2, invalid year comprehensive efficiency was less than 1, in the case of variable returns to scale, input redundancy, the inputs and outputs appear not harmonious, disconnect between input and output, did not reach the best state. By cutting the input in agriculture to make production efficiency to achieve the optimal state. In 1997 effective irrigation area, fertilizer input and agricultural output in redundancy and redundancy ware $10515 \mathrm{hm} 2,28320 \mathrm{t}$ and 059.2 million Yuan respectively. It showed that in 1997, when effective irrigation area, fertilizer input to reduce $10515 \mathrm{hm} 2,10515 \mathrm{t}$, agricultural output value to reduce 059.2 million Yuan, agricultural input and output will reach the most optimal configuration, to achieve optimal efficiency in Guizhou province. The amount of redundancy in 2006, 2007, 2008, 2007 and 2011were showed in table 3 , it could be seen in Guizhou province in the year of invalid, crop planting area, fertilizer input and pesticide use of redundancy were bigger, it showed the current agricultural development in guizhou overdependence on pure increasing the food crops planting area, excessive chemical fertilizers and pesticides to stimulate agricultural growth, there were the phenomenon of fertilizer and pesticide overuse. That had to do with the current low cultural quality of farmers, agricultural materials input basically rely on experience rather than by scientific measurement. At the same time, excessive use of fertilizers and pesticides were also the main factors of agricultural non-point source pollution, not 
consistent with the current construction of ecological civilization, and the background of developing ecological agriculture in Guizhou.

Table 3 The amount of redundancy and reduce

\begin{tabular}{|l|l|l|l|l|l|l|l|}
\hline MDU & \multicolumn{1}{|c|}{$\begin{array}{c}\text { Effective } \\
\text { irrigated area } \\
\text { (thousand } \mathrm{hm}^{2} \text { ) }\end{array}$} & $\begin{array}{c}\text { Crop } \\
\text { planting } \\
\text { area } \\
\text { (thousand } \\
\mathrm{hm}^{2} \text { ) }\end{array}$ & $\begin{array}{c}\text { Fertilizer } \\
\text { inputs (Ten } \\
\text { thousand t) }\end{array}$ & $\begin{array}{c}\text { amount of } \\
\text { pesticide } \\
(\mathrm{t})\end{array}$ & $\begin{array}{c}\text { Rural working } \\
\text { population } \\
\text { (Ten } \\
\text { thousand) }\end{array}$ & $\begin{array}{c}\text { Agricultural } \\
\text { output (Hundred } \\
\text { million Yuan) }\end{array}$ & $\begin{array}{c}\text { Food } \\
\text { production (Ten } \\
\text { thousand t) }\end{array}$ \\
\hline 1997 & 10.515 & 0.000 & 2.832 & 0.000 & 0.000 & 0.592 & 0.000 \\
\hline 2006 & 0.000 & 727.887 & 1.600 & 919.741 & 0.000 & 0.000 & 104.281 \\
\hline 2007 & 0.000 & 435.616 & 1.578 & 482.016 & 0.000 & 0.000 & 19.718 \\
\hline 2008 & 14.690 & 309.954 & 0.000 & 1545.094 & 29.446 & 0.000 & 0.000 \\
\hline 2010 & 165.663 & 565.965 & 0.000 & 1082.513 & 11.473 & 0.000 & 0.000 \\
\hline 2011 & 39.404 & 0.000 & 3.328 & 1601.517 & 0.000 & 0.000 & 189.638 \\
\hline 均值 & 13.545 & 119.966 & 0.549 & 331.228 & 2.407 & 0.035 & 18.449 \\
\hline
\end{tabular}

\section{Conclusion and discussion}

Using the DEA model, to measure the input and output efficiency of agriculture in Guizhou and analyzed, The main conclusions were as follows:

(1)Nearly 17 years in Guizhou province the fluctuation of comprehensive efficiency of agricultural input and output was small. the pure technical efficiency is not the main factors affected agriculture input and output efficiency in Guizhou province. there were 12 years of pure scale efficiency value less than 1, pure scale efficiency is invalid. The scale of agricultural input and output and configuration were not reasonable, expanding the scale of production could get the best economies of scale. the scale efficiency were the main factors influencing the overall efficiency of agricultural input and output in Guizhou.

(2) in the case of variable returns to scale, the were input redundancy ,the status of the inputs and outputs appear not harmonious, and disconnect between input and output in efficiency invalid year. The redundancy of crop planting area, fertilizer input and pesticide use were bigger. By cutting the input redundancy to make agricultural production efficiency achieve the optimal state.

(3) In this paper, by using DEA model, from the perspective of capital, labor, land in economics ,select indexes to analyze agricultural input and output efficiency of Guizhou province, Having important reference value to sustainable development of agriculture in Guizhou. Due to the reliability of the data, analysis unavoidably exist shortcomings, but not affect analysis of the overall characteristics of the agricultural efficiency, agricultural input and output efficiency relating to the micro (plant production capacity, irrigation, etc.) and macro scales (management measures, climate change, etc.), Therefore, how to incorporate the micro scale and macro scale to construct index system of agricultural input and output efficiency, will be the next step is still need to improve. Will be the direction need to work on.

\section{Acknowledgements}

This work was financially supported by The key discipline of environmental science features/natural geographical special fun Guizhou; 


\section{References}

[1]KUANG Yuanpei,LIAN Dapeng ,LUO Hehua. Empirical Analysis on Relations Between Resource-reservation and Environment. Journal of Industrial Technological Economics,Vol.11(2010),P.62-65.

[2]WANG Bing, YANG Ha, ZHU Ning. Agricultural Efficiency and Total Factor Productivity Growth in China's Provincial Economies. Southern Economy, Vol.10(2011),p. 12-27.

[3]WANG Xueyuan, ZHAO Liange. China's agricultural water use efficiency and influencing factors. Issues in Agricultural Economy. Vol.3 (2008), p.10-20.

[4]LIU Yu,DU Jiang,ZHANG Junbiao. Estimation on Utilization Efficiency of Agricultural Water Resource in Hubei Province. China population, resources and environment. Vol. 17(2007), p.60-66.

[5]LI Jing,LI Jingyu. Fertilizer Using Efficiency of China's Grain Production and Its Determining Factors. Research of Agricultural Modernization. Vol. ,32 (2011),p.566-570. 